\title{
Differential Activity for Animals and Manipulable Objects in the Anterior Temporal Lobes
}

\section{Citation}

Anzellotti, Stefano, Bradford Z. Mahon, Jens Schwarzbach, and Alfonso Caramazza. 2011. Differential activity for animals and manipulable objects in the anterior temporal lobes. Journal of Cognitive Neuroscience 23(8): 2059-2067.

\section{Published Version}

dx.doi.org/10.1162/jocn.2010.21567

\section{Permanent link}

http://nrs.harvard.edu/urn-3:HUL.InstRepos:5241364

\section{Terms of Use}

This article was downloaded from Harvard University's DASH repository, and is made available under the terms and conditions applicable to Open Access Policy Articles, as set forth at http:// nrs.harvard.edu/urn-3:HUL.InstRepos:dash.current.terms-of-use\#OAP

\section{Share Your Story}

The Harvard community has made this article openly available.

Please share how this access benefits you. Submit a story.

Accessibility 


\section{ATL ACTIVITY FOR ANIMALS AND TOOLS}

Running head: ATL ACTIVITY FOR ANIMALS AND TOOLS

Differential activity for animals and manipulable objects in the anterior temporal lobes

Stefano Anzellotti ${ }^{1,2}$, Bradford Z. Mahon ${ }^{1,3}$, Jens Schwarzbach ${ }^{2,4}$, and Alfonso Caramazza ${ }^{1,2}$

${ }^{1}$ Center for Mind/Brain Sciences (CIMeC), University of Trento, Italy

${ }^{2}$ Cognitive Neuropsychology Laboratory, Harvard University, Cambridge, USA

${ }^{3}$ Department of Brain and Cognitive Sciences, University of Rochester, USA

${ }^{4}$ Department of Cognitive Science and Education, University of Trento, Italy

Address of Correspondence:

Stefano Anzellotti

Cognitive Neuropsychology Laboratory

Harvard University

William James Hall, Room 940

33 Kirkland Street

Cambridge, MA 02138

USA

E-mail: sanzell@wjh.harvard.edu 


\title{
ATL ACTIVITY FOR ANIMALS AND TOOLS
}

\author{
Abstract: \\ Neuropsychological evidence has highlighted the role of the anterior temporal lobes in the \\ processing of conceptual knowledge. That putative role is only beginning to be investigated with \\ fMRI as methodological advances are able to compensate for well known susceptibility artifacts \\ that affect the quality of the BOLD signal. In the present paper, we describe differential BOLD \\ activation for pictures of animals and manipulable objects in the anterior temporal lobes, consistent \\ with previous neuropsychological findings. Furthermore, we find that the pattern of BOLD signal in \\ the anterior temporal lobes is qualitatively different from that in the fusiform gyri. The latter regions \\ are activated to different extents but always above baseline by images of the preferred and of the \\ non-preferred categories, while the anterior temporal lobes tend to be activated by images of the \\ preferred category and deactivated (BOLD below baseline) by images of the non-preferred \\ category. In our experimental design, we also manipulated the decision that participants made over \\ stimuli from the different semantic categories. We found that in the right temporal pole, the BOLD \\ signal shows some evidence of being modulated by the task that participants were asked to perform, \\ while BOLD activity in more posterior regions (e.g. the fusiform gyri) is not modulated by the task. \\ These results reconcile the fMRI literature with the neuropsychological findings of deficits for \\ animals after damage to the right temporal pole and suggest that anterior and posterior regions \\ within the temporal lobes involved in object processing perform qualitatively different \\ computations.
}




\section{ATL ACTIVITY FOR ANIMALS AND TOOLS}

\section{Introduction}

Brain damage can lead to differential impairment of different semantic categories of objects (Nielsen 1946; Warrington \& McCarthy 1983; Warrington \& Shallice 1984). The semantic categories that are observed to be disproportionately impaired include conspecifics (Ellis, Young, \& Critchley, 1989; Miceli, Capasso, Daniele, Esposito, Magarelli \& Tomaiuolo, 2000), animals (Caramazza \& Shelton 1998; Blundo, Ricci, \& Miller, L. 2006), fruit and vegetables (Hart, Berndt \& Caramazza, 1985; Samson \& Pillon, 2003) and nonliving objects (Caramazza \& Hillis, 1991; Sacchett \& Humphreys, 1992; Laiacona \& Capitani, 2001). Lesion-deficit correlation studies of brain damaged patients (Damasio, Grabowski, Tranel, Hichwa, \& Damasio, 1996; Tranel, Damasio, \& Damasio, 1997; Damasio, Tranel., Grabowski, Adolphs, \& Damasio, 2004) and reviews of the available neuropsychological data (Gainotti 2000; Capitani, Laiacona, Mahon, \& Caramazza, 2003) have shown that deficits for different categories of objects tend to be associated with specific loci of brain lesion, despite the fact that deficits for knowledge of a category of objects can sometimes derive from lesions to different brain areas. In particular, impairments for knowledge of living things frequently occur as a consequence of lesions in the anterior temporal lobes, while impairments for manipulable objects are usually associated with damage to the posterior middle temporal gyrus (MTG).

For instance, in a study with 152 patients affected by various neurodegenerative diseases, Brambati and colleagues found that naming accuracy for pictures of household items, vehicles and manipulable objects correlated with grey matter volume in the left middle temporal gyrus (MTG), while naming accuracy for animals and fruit correlated with grey matter volume in the medial portion of the right anterior temporal pole (Brambati, Myers, Wilson, Rankin, Allison, Rosen, Miller, \& Gorno-Tempini, 2006). A parallel literature using functional imaging has described dissociable networks of brain regions 


\section{ATL ACTIVITY FOR ANIMALS AND TOOLS}

that are differentially engaged by stimuli from different semantic categories. Greater activity for manipulable objects has been found in parietal areas, in the medial fusiform gyri and in the left MTG (Chao, Martin, \& Haxby, 1999; Chao, Haxby, \& Martin, 1999; Martin \& Chao 2001; Mahon, Milleville, Negri, Rumiati, Caramazza, \& Martin, 2007; Mahon, Anzellotti, Schwarzbach, Zampini, \& Caramazza, 2009), consistent with the neuropsychological evidence. On the other hand, preferential activity for animals has been found with fMRI in the lateral fusiform gyri and in the right STS (Chao et al. 1999a; Chao et al. 1999b; Martin \& Chao 2001), but to our knowledge never in the anterior temporal lobes, perhaps due to the known susceptibility issues in that area (Devlin, Russell, Davis, Price, Wilson, Moss, Matthews, \& Tyler, 2000).

In the present study, we wanted to investigate whether differences in the BOLD signal in response to animals and manipulable objects could be detected in the anterior temporal lobes, paying particular attention to the quality of the signal. We presented greyscale images of animals and manipulable objects to 12 volunteers. On half of the trials, participants were asked to report whether the object in the image was an animal; on the remaining trials they were asked to report whether it was a manipulable object (yes/no button press). To anticipate our results, we observed, in agreement with the lesion study by Brambati and colleagues (2006), greater BOLD signal in response to animals than to manipulable objects in the medial portion of the right anterior temporal pole, and greater BOLD signal in response to manipulable objects in a lateral area of the left anterior temporal lobe. Previous PET studies, which do not have the susceptibility artifacts associated with fMRI, have reported greater activity in the temporal poles for natural kinds than for man made objects (Mummery, Patterson, Hodges, \& Wise 1996; Moore \& Price 1999; Damasio et al. 2004; Kellenbach, Hovius, \& Patterson 2005; Devlin, Moore, Mummery, Gorno-Tempini, Phillips, Noppeney, Frackowiak, Friston, \& Price 2002). With the present study, we investigated in greater detail the response properties of the anterior temporal areas that showed preferential BOLD 


\section{ATL ACTIVITY FOR ANIMALS AND TOOLS}

responses for animals and man made objects, looking at whether information at different levels in the ventral stream is accessed flexibly as a function of the behavioral goals of the individuals. To address this issue, we compared the BOLD signal during object processing when the participants answered two questions: "Is the object in the image an animal?" and "Is the object in the image a tool?". The anterior temporal lobes showed greater task sensitivity than the posterior temporal lobes. This difference suggests that processing in the posterior temporal areas is more "automatic", providing a perceptual analysis that is relatively independent of the specific behavioral goals of the individual, while the anterior temporal areas may process information more flexibly as a function of the goals of the individual. The present fMRI findings go a step farther in the investigation of the roles played by different areas within the temporal lobes, distinguishing anterior inferotemporal regions from posterior inferotemporal regions on the basis of their different patterns of BOLD signal with respect to baseline. The posterior regions in the ventral stream were more active than baseline for objects of both the preferred and the non-preferred category, while the BOLD signal in anterior temporal areas was, if anything, below baseline for objects belonging to the non-preferred category. We speculate that this might be due to the retrieval of object representations during mindwandering. Whenever mind-wandering takes place (e.g. during rest), the object representations in the anterior temporal lobes would be retrieved, leading to an increase in the BOLD signal. However, because of random variation, the object representations retrieved during mind-wandering would belong sometimes to a category, and sometimes to others. Therefore, the BOLD signal in a region within the ATL during rest would result on average lower than during processing of objects of the preferred category, but higher than during processing of objects of the non-preferred category.

\section{Methods}

\section{Participants}

Twelve participants between age 18 and 32 (all native Italian speakers) took part in the 


\section{ATL ACTIVITY FOR ANIMALS AND TOOLS}

experiment. Data from one participant were excluded from the analysis due to excessive head motion. Thus, the data of 11 participants were analyzed. The participants' consent was obtained according to the Declaration of Helsinki (BMJ 1991; 302: 1194) and the project was approved by Human Subjects Committees at the University of Trento and Harvard University.

\section{Stimuli}

The set of stimuli consisted of 128 greyscale images, of which 64 depicted animals and 64 tools. There were 32 different basic-level animals and 32 basic-level tools, with two exemplars from each basic-level. We presented two pictures for each object type, which depicted different exemplars of that object type. For instance, for the object type "hammer", we had pictures of two different hammers.

Stimuli were presented with Matlab PTB (Brainard, 1997; Pelli, 1997) with the in-house add-on ASF (available from JS), employing an Epson EMP 9000 projector. Images were projected on a frosted screen at the top of the bore, viewed through a mirror attached to the head coil.

\section{Experimental design}

Structure of the trial. Each trial was composed of five parts (see Supplementary Figure 1): blank with letter (400ms-800ms) - image (500ms) - delay, blank with letter $(2 \mathrm{~s}-8 \mathrm{~s})$ - response cue (400ms-800ms) - blank with letter (4s-8s). The timings were generated from distributions with hyperbolic density. On each trial, a single picture was presented. The participants were asked to decide whether a given picture was an animal or a tool (push button with right index finger for yes, and left index finger for no). Specifically, the participants had to answer one of the two questions: "Is the object in the image an animal?" (“L'oggetto nell'immagine e' un animale?") or "Is the object in the image a tool?" (“L'oggetto nell'immagine e' uno strumento?”). Participants were asked to wait until after the visual cue (a fixation cross) before responding.

Order of the questions. Participants answered the same question for 32 consecutive trials. 


\section{ATL ACTIVITY FOR ANIMALS AND TOOLS}

Thus, one question (e.g., is it an animal?) was presented at the beginning of the run and answered during the first half of the trials (32); then participants answered the other question (e.g., is it a tool?) for the remaining half of the trials. Between trials, a blank screen with a letter in the middle ("A" for "animale" (animal), "S" for "strumento" (tool)) was presented, to remind participants of the question that they should be answering. The order of the questions in the runs was counterbalanced within and between participants, using two different orders of questionpresentation in the experiment. One half of the participants were presented with the questions in the order T(ool)A(nimal)-AT-AT-TA, while the other half were presented the questions in the order ATTA-TA-AT. The dash denotes the separation between runs). Every image was presented with both questions for every participant, and this happened in different orders for the participants in the two halves. That is, if for a given participant a given image was shown with the question "Is it an animal?" and later in the session with the question "Is it a tool?", a different participant was shown that same image first with the question "Is it a tool?" and then with the question "Is it an animal?". This design ensured that all of the stimuli were evenly counterbalanced across participants.

Structure of the runs. The experiment was composed of four runs, each run lasting approximately 15 minutes. The stimuli were divided into two groups, A and B; each group (A and B) contained both exemplars of a given item. All items in group A were presented in each of the runs 1 and 3, and all items in group B were presented in each of the runs 2 and 4. Each run consisted of 64 trials. Stimuli were presented visually, subtending a visual angle of approximately 10 degrees.

Within each run, images of two different exemplars of every item type were presented. Because of the distribution of the questions, within a run, items repeated across question tended to have more trials between them than item types repeated within question. Therefore, we divided the images of item types repeated across question in two groups (repeated near, repeated far) so as to be 


\section{ATL ACTIVITY FOR ANIMALS AND TOOLS}

able to match for number of intervening trials for the images repeated within question.

\section{Data Acquisition and Analysis}

MRI scanning parameters. The data were collected on a Bruker BioSpin MedSpec 4T at the Center for Mind/Brain Sciences $(\mathrm{CIMeC})$ of the University of Trento using a US instruments 8 channel phased array head coil. Before collecting functional data, a high $\left(1 \times 1 \times 1 \mathrm{~mm}^{3}\right)$ resolution T1-weighted 3D MPRAGE anatomical sequence was performed (sagittal slice orientation, centric Phase Encoding, image matrix $=256 \times 224($ Read $\times$ Phase $), F o V=256 \mathrm{~mm} \times 224 \mathrm{~mm}(\operatorname{Read} \mathrm{x}$ Phase), 176 partitions with $1 \mathrm{~mm}$ thickness, GRAPPA acquisition with acceleration factor $=2$, duration $=5.36$ minutes, $\mathrm{TR}=2700, \mathrm{TE}=4.18, \mathrm{TI}=1020 \mathrm{~ms}, 7^{\circ}$ flip angle). Functional data were collected using an echo planar 2D imaging sequence with phase over-sampling (Image matrix: $70 \mathrm{x}$ 64, TR: 2250ms TE: $33 \mathrm{~ms}$, Flip angle: $76^{\circ}$, Slice thickness $=3 \mathrm{~mm}$, gap $=.45 \mathrm{~mm}$, with $3 \mathrm{mmx} 3 \mathrm{~mm}$ in plane resolution). Volumes were acquired in the axial plane, in 37 slices. The order of slice acquisition was ascending interleaved odd-even.

Analysis of temporal signal-to-noise ratio (TSNR). Given the known susceptibility issues associated with fMRI applied to frontotemporal regions (Devlin et al. 2000), we calculated TSNR maps to ensure that the quality of the signal in the anterior temporal lobes was adequate to detect BOLD signal. We thresholded the TSNR map for every participant and run at 40, a value indicated by simulations as sufficient to detect effects reliably with fMRI (Murphy, Bodzurka, \& Bandettini, 2007; see also Simmons, Reddish, Bellgowan, \& Martin, 2009). The maps indicated high TSNR in individual participants, greatly exceeding the threshold of 40 in most of the anterior temporal lobes (see for instance Figure 1b). To check that signal quality in the anterior temporal lobes was consistent across participants we generated probability maps indicating for each voxel the percentage of participants that showed TSNR above the threshold of 40 in that voxel (see Figure 1c). TSNR in the ATL was above threshold in the majority of the participants and runs, indicating 


\section{ATL ACTIVITY FOR ANIMALS AND TOOLS}

that the quality of the signal was stable.

Data analysis. The data were analyzed using Brain Voyager (v. 1.10) and MATLAB (release 2008b). The first two volumes of functional data from each run were discarded before the analysis. Functional data were preprocessed with the following steps (reported in the order in which they were performed): slice time correction (sinc interpolation), motion correction (trilinear interpolation) with respect to the first (remaining) volume in the run, and linear trend removal in the temporal domain (cutoff: 3 cycles within the run). They were then coregistered (after contrast inversion of the first remaining volume) to the high-resolution deskulled anatomy on a participantby-participant basis in native space. For each individual participant, echo-planar and anatomical volumes were transformed into the standardized Talairach and Tournoux (1988) space. Data were smoothed with a Gaussian spatial filter ( $4.5 \mathrm{~mm}$ full-width at half-maximum). The presentations of the images were modeled as events. A standard dual gamma hemodynamic response function was used to convolve the events in the experiment.

The data were modeled with a random effects GLM. As described in the section about the design, in each run every item type was presented twice, and in the two presentations two different images (i.e., different exemplars) of that item type were shown. We modeled these properties of the design, which led to 26 regressors overall: 12 for the animal stimuli (exemplar 1, exemplar 2 by presentation 1, presentation 2 by presented within question, presented across question (near or far) ), 12 for the tool stimuli (analogous to the animal case), one for the response cue and one for the presentation of the questions.

The GLM was masked with the deskulled average brain extending anteriorly to $y=-75$ in the Talairach coordinate system (see Pietrini, Furey, Ricciardi, Gobbini, Wu, Cohen, Guazzelli, \& Haxby, 2004) so as not to bias the analysis by effects in early visual regions, such as those described in Martin et al. 1996, Martin \& Chao 2001 and Damasio et al. 2004; see the supplementary 


\section{ATL ACTIVITY FOR ANIMALS AND TOOLS}

materials for a figure of the unmasked data). The threshold was corrected for cluster size using alpha-sim, in the Brain Voyager Cluster-level plug-in (1000 iterations). Custom MATLAB software utilizing the BVQX toolbox for MATLAB was employed to perform further analyses on the data extracted from Brain Voyager (Figures 1,3).

\section{Results}

\section{Analysis of category effects}

Using the random effects GLM, we performed an analysis of category effects based on the contrast of all animal stimuli vs all tool stimuli, collapsing across the other nested factors. In Table 1 we report the regions that showed significantly different activity $(p<0.05$ corrected) for the two categories of objects, the coordinates of the centers of mass and the numbers of voxels. We found greater activity for animals than for tools in the right fusiform and STS ( $<<0.01$ corrected) and greater activity for tools in the medial fusiform gyrus bilaterally $(\mathrm{p}<0.001$ corrected). In agreement with lesion studies (Brambati et al. 2006), we also find greater BOLD signal for tools than for animals in the left MTG $(\mathrm{p}<0.001$ corrected), a region frequently associated with impairments for the recognition of nonliving objects (Gainotti 2000; Brambati et al. 2006).

In addition, we found greater BOLD signal for animal pictures in the right temporal pole, significant at $\mathrm{p}<0.001$ (corrected). The identified area is compatible with a broader region reported by Brambati and colleagues (2006) where volume of grey matter correlates with patient performance at animal recognition (Figure 4). We also find greater BOLD signal for tools in the left anterior temporal lobe $(\mathrm{p}<0.005$ corrected).

\section{Dissociation between anterior and posterior temporal regions}

Within the ventral temporal lobes, we found a qualitatively distinct pattern of BOLD responses in posterior and anterior regions. Responses to animals and tools in the anterior temporal lobes are centered on the baseline, while responses to both animals and tools activate the more 


\section{ATL ACTIVITY FOR ANIMALS AND TOOLS}

posterior areas well above baseline (see Figure 3). This pattern is represented by the significant differences between the means of the betas in the anterior and posterior regions, collapsing together the animal and tool conditions. Comparing the mean activity of the right temporal pole and of the left anterior temporal lobe separately with each of the three areas in the fusiform, the differences are highly significant ( $\mathrm{p}<0.001$ corrected in all comparisons). On the other hand, the difference between the means of the right temporal pole and the left ATL was not significant ( $p>0.05$ corrected). In particular, the fusiform gyri showed BOLD signal above baseline for pictures for both animals and tools, with greater BOLD signal for the preferred category and smaller BOLD signal for the nonpreferred category. Instead, activity in the anterior temporal lobes showed activity around baseline, with a trend towards a decrease below baseline of the BOLD signal in response to the non-preferred category (Figure 3).

\section{Question effects}

We were interested in studying whether the BOLD signal in the ventral stream is modulated as a function of the question asked (is it an animal?, is it a tool?), and in which regions this might be the case. Inside the ROIs defined above, we ran an ANOVA to test for question effects. The BOLD response in the fusiform gyrus bilaterally did not differ significantly for the two questions asked ( $>0.1$ ). On the other hand, activity in the right temporal pole was significantly modulated by question type $\left(\mathrm{t}_{1,10}=-2.25, \mathrm{p}<0.05\right.$, see Table 2$)$. Importantly, in the right temporal pole there were no interaction effects of question by any of the other dimensions manipulated in the experiment (ps $>0.1$ ). In particular, the interaction between question type and category of the stimulus was nonsignificant $\left(\mathrm{F}_{1,10}=0.01, \mathrm{p}=0.94\right)$. Furthermore, the question dimension was orthogonal to the category dimension (and to the item dimension, as both questions were asked for all items in every participant). For these reasons, the test of question effects is independent of the way in which we selected the voxels. 


\section{ATL ACTIVITY FOR ANIMALS AND TOOLS}

\section{Discussion}

Our observations replicate several studies of object recognition showing differential BOLD signal in response to animal pictures and pictures of manipulable objects (see Martin 2007 for a review). In particular, we replicate previous reports of greater activity for tools in the medial fusiform gyri, the left MTG and parietal cortex, as well as reports of greater activity for animals in the right lateral fusiform and the right STS (Chao et al. 1999a; Chao et al. 1999b; Martin \& Chao 2001; Mahon et al. 2007).

The observation of differential activation for animal pictures in the right medial temporal pole reconciles the results of functional imaging with neuropsychological findings of category specific deficits after damage to the temporal poles (e.g. Brambati et al. 2006; Noppeney, Patterson, Tyler, Moss, Stamatakis, Bright, Mummery, \& Price, 2007; Papagno, Capasso, \& Miceli, 2009). This result motivates the use of fMRI longitudinally in patients to study the deterioration of object knowledge with the progression of neurodegenerative diseases.

We observed a left hemisphere bias for manipulable objects and a right hemisphere bias for living things in the anterior temporal lobes, in line with the differential involvement of the left and right posterior temporal lobes in the processing of objects from different categories. Thus, it seems that the pattern of greater activity in the right hemisphere for animals and greater activity in the left hemisphere for tools (see Martin and Chao 2001, Mahon et al. 2007) generalizes from the posterior temporal lobe to the anterior temporal lobe.

We detected greater BOLD signal for manipulable objects than for animals in a more posterior region of the left anterior temporal lobe, not reported to our knowledge in the PET studies that described a right anterotemporal locus of greater activity for animals. The location of this region is consistent with a recent neuropsychological report of deficit for tool naming after left ATL resection (Bi, Wei, Wu, Han, Jiang, \& Caramazza, in press). The finding of a region more responsive for 


\section{ATL ACTIVITY FOR ANIMALS AND TOOLS}

manipulable objects than for animals in the left anterior temporal lobe converges with the finding of a region more active for knowledge of context of use of manipulable objects versus knowledge of action (Canessa, Borgo, Cappa, Perani, Falini, Buccino, Tettamanti, \& Shallice, 2007).

A recent fMRI study has shown that the anterior temporal lobes are more active when participants learn facts about unfamiliar people than when they learn facts about hammers or buildings (Simmons et al. 2009). The authors propose that the ATLs are part of a domain-specific social cognition system. This hypothesis, however, does not account for the deficits for animals, and especially for plants, observed as a consequence of ATL damage (e.g. De Renzi \& Lucchelli 1994). Without excluding an important role of the ATLs for knowledge about persons and social cognition, our results support the view that the ATLs are also involved in processing objects belonging to other semantic categories.

Converging with the findings by Simmons and colleagues (2009), Rajimehr and colleagues (2009) described a region in the right anterior temporal lobe that shows greater BOLD signal in response to faces than to place stimuli. It remains an open question whether and to which extent the regions described by Simmons and colleagues and by Rajimehr and colleagues and the animal area that we describe overlap. This question would be best addressed by studies that show images of both animals and faces, since they would permit a comparison of the different regions within single subjects thus avoiding the difficulties deriving from the intersubject variability of the foci of activity.

We find a qualitatively different pattern of BOLD signal in the anterior and posterior regions of the ventral temporal cortex. The pattern of activity in posterior regions is well above baseline for both animals and tools. On the other hand, the pattern of activity in anterior regions is centered around baseline, with a trend toward a decrease in the BOLD signal for the non-preferred category. Importantly, under the standard assumption that noise is symmetrically distributed around the actual 


\section{ATL ACTIVITY FOR ANIMALS AND TOOLS}

value, the difference in the mean BOLD signal relative to baseline in the PTL with respect to the ATL is unlikely to be explained by a greater amount of noise in anterior areas. This is because greater levels of noise in the ATL would lead to a larger variance in the BOLD signal reducing the significance level, but they would not alter the observed mean value.

The neural significance of BOLD signal below baseline is a complex issue (Harel, Lee, Nagaoka, Kim, \& Kim, 2002; Kannurpatti \& Biswal 2004; Raichle, MacLeod, Snyder, Powers, Gusnard \& Shulman, 2001; Gusnard \& Raichle 2001; Smith, Williams, \& Singh, 2004). However, a recent paper (Shmuel et al. 2006) showed that negative BOLD can reflect neural activation below baseline. Shmuel and colleagues suggest that negative BOLD responses that are located in the grey matter and far from other positive BOLD responses may be interpreted as reflecting a decrease in neural activity. The areas in the anterior temporal lobes showing a trend towards a decrease in the BOLD signal are most likely located in the grey matter and are far from other positive BOLD responses; therefore the same interpretation may be tentatively applied to our findings. In this study, the different pattern of BOLD signal in the posterior and anterior areas of the ventral temporal cortex could be due to relatively high activity in the anterior temporal areas during baseline. In fact, portions of the anterior temporal lobes are part of the default network (Ingvar 1974, 1979; see Buckner, Andrews-Hanna \& Schacter, 2008 for a review) and it is thus possible that the areas we found are within a set of regions that show greater activity during rest than during performance of most active tasks. It is possible that the anterior temporal lobes are particularly active even when we retrieve representations of objects "top down", in the absence of a corresponding bottom up sensory stimulation. Mind wandering also involves the retrieval of object representations, and according to this account it would thereby raise the BOLD signal in the ATL during rest. Another possibility is that the BOLD signal in the anterior temporal lobes reflects active 


\section{ATL ACTIVITY FOR ANIMALS AND TOOLS}

suppression of the non-preferred category in the anterior temporal lobes but not in the fusiform gyri (see Egner \& Hirsch 2005). These two possibilities are not mutually exclusive.

The BOLD signal in posterior areas of the temporal lobe (e.g. the fusiform gyri) did not show any significant modulation by task. The BOLD signal in the right temporal pole, on the other hand, was mildly but significantly modulated by question type, suggesting a greater influence of top-down connections. A study by Rogers and colleagues (2005) has shown task-dependent modulations of the activity in posterior temporal areas. The results obtained by Rogers and colleagues are compatible with our findings. The different tasks used in the present experiment were matched very closely: they required categorization at a similar level of specificity and the relative instructions differed by a single word. Therefore, our study does not imply that posterior areas are totally unaffected by any possible task differences, but rather it shows that by choosing carefully matched tasks it is possible to reveal differences between posterior and anterior areas in terms of their task sensitivity. Further studies will be needed to deepen our understanding of how different types of tasks modulate ATL activity, and what role this modulation plays in the performance of the tasks. In conclusion, dimensions other than semantic category might differentiate anterior from posterior regions in the ventral temporal lobe. On the other hand, semantic category could be a factor shaping neural organization within different levels along the anterior to posterior axis. 


\section{ATL ACTIVITY FOR ANIMALS AND TOOLS}

Bellgowan, P.S.F., Bandettini, P.A., van Gelderen, P., Martin, A. and Bodurka, J. (2006). Improved BOLD detection in the medial temporal region using parallel imaging and voxel volume reduction. NeuroImage 29 (2006) 1244 - 1251. doi:10.1016/j.neuroimage.2005.08.042

Bi, Y., Wei, T., Wu, C., Han, Z., Jiang, T. and Caramazza, A. (In press). The role of the left anterior temporal lobe in language processing revisited: Evidence from an individual with ATL resection. doi:10.1016/j.cortex.2009.12.002

Blundo, C., Ricci, M., and Miller, L. (2006). Category-specific knowledge deficit for animals in a patient with herpes simplex encephalitis. Cognitive Neuropsychology 2006, 23 (8), 12481268

Brainard, D. H. (1997) The Psychophysics Toolbox, Spatial Vision 10:433-436.

Brambati, S.M., Myers, D., Wilson, A., Rankin,K. P., Allison, S. C., Rosen, H. J., Miller, B. L., and Gorno-Tempini, M. L. (2006). The Anatomy of Category-specific Object Naming in Neurodegenerative Diseases. Journal of Cognitive Neuroscience 18:10, pp. 1644-1653

Buckner, R., Andrews-Hanna, J., \& Schacter, D. (2008). The brain's default network: Anatomy, function and relevance to disease. Annals of the New York Academy of Sciences, 1124, 1-38.

Canessa, N., Borgo, F., Cappa, S.F., Perani, D., Falini, A., Buccino, G., Tettamanti, M. and Shallice, T. (2007). The Different Neural Correlates of Action and Functional Knowledge in Semantic Memory: An fMRI Study. Cerebral Cortex doi:10.1093/cercor/bhm110

Capitani, E., Laiacona, M., Mahon, B., \& Caramazza, A. (2003). What are the facts of semantic categoryspecific deficits? A critical review of the clinical evidence. Cognitive Neuropsychology, 20, 213-261.

Caramazza, A., and Hillis, A.E. (1991). Lexical organization of nouns and verbs in the brain. 


\section{ATL ACTIVITY FOR ANIMALS AND TOOLS}

Nature 349, 788 - 790 (28 February 1991); doi:10.1038/349788a0

Caramazza, A. and Shelton, J.R. (1998). Domain-Specific Knowledge Systems in the Brain: The Animate-Inanimate Distinction. Journal of Cognitive Neuroscience 10:1, pp. 1-34

Chao, L.L., Martin, A. and Haxby, J.V. (1999). Are face-responsive regions selective only for faces? NeuroReport 10, 2945-2950 (1999)

Chao, L.L. Haxby, J.V., and Martin, A.(1999). Attribute-based neural substrates in temporal cortex for perceiving and knowing about objects. Nature Neuroscience, volume 2, no. 10, October 1999

Damasio, H., Grabowski, T.J., Tranel., D., Hichwa, R.D., and Damasio, A.R. (1996). A neural basis for lexical retrieval. Nature, Vol 380, 11 April 1996

Damasio, H., Tranel., D., Grabowski, T.J., Adolphs, R., and Damasio, A. (2004). Neural systems behind word and concept retrieval. Cognition 92 (2004) 179-229 doi:10.1016/j.cognition.2002.07.001

De Renzi, E., \& Lucchelli, F. (1994). Are semantic systems separately represented in the brain? The case of living category impairment. Cortex, 30, 3-25.

Devlin, J.T., Russell, R.P., Davis, M.H., Price, C.J., Wilson, J., Moss, H.E., Matthews, P.M., and Tyler, L.K. (2000). Susceptibility-Induced Loss of Signal: Comparing PET and fMRI on a Semantic Task. NeuroImage 11, 589-600 (2000) doi:10.1006/nimg.2000.0595

Devlin, J.T., Moore, C. J., Mummery, C. J., Gorno-Tempini, M. L., Phillips, J. A. Noppeney, U., Frackowiak, R. S. J., Friston, K. J. and Price, C. J. (2002). Anatomic Constraints on Cognitive Theories of Category Specificity. NeuroImage 15, 675-685

Egner T, Hirsch J. (2005). Cognitive control mechanisms resolve conflict through cortical 


\section{ATL ACTIVITY FOR ANIMALS AND TOOLS}

amplification of task-relevant information. Nat Neurosci 8:1784-90.

Ellis, A.W., Young, A.W., and Critchley, E.M.R. (1989). Loss of memory for people following temporal lobe damage. Brain (1989) 112, 1469-1483

Gainotti, G. (2000). What the locus of brain lesion tells us about the nature of the cognitive defect underlying category-specific disorders: a review. Cortex, (2000) 36, 539-559

Gusnard, D.A. \& Raichle, M.E. Searching for a baseline: functional imaging and the resting human brain. Nat. Rev. Neurosci. 2, 685-694 (2001).

Harel, N., Lee, S.P., Nagaoka, T., Kim, D.S. \& Kim, S.G. Origin of negative blood oxygenation level-dependent fMRI signals. J. Cereb. Blood Flow Metab. 22, 908-917 (2002).

Hart J Jr, Berndt RS, Caramazza A. 1985. Category-specific naming deficit following cerebral infarction. Nature 316:439-40

Hodges, J.R., Patterson, K., Oxbury, S., and Funnell, E. (1992). Semantic dementia. Progressive fluent aphasia with temporal lobe atrophy. Brain (1992), 115, 1783-1806

Ingvar, D. H. (1974). Patterns of brain activity revealed by measurements of regional cerebral blood flow. Alfred Benzon Symposium VIII . Copenhagen.

Ingvar, D. H. (1979). "Hyperfrontal” distribution of the cerebral grey matter flow in resting wakefulness: on the functional anatomy of the conscious state. Acta Neurol. Scand., 60, 1225.

Kannurpatti, S.S. and Biswal, B.B. Negative functional response to sensory stimulation and its origins. J. Cereb. Blood Flow Metab. 24, 703-712 (2004).

Kellenbach, M.L., Hovius, M., and Patterson, K. 2005. A PET study of visual and semantic knowledge about objects. Cortex, (2005) 41, 121-132 


\section{ATL ACTIVITY FOR ANIMALS AND TOOLS}

Laiacona, M. and Capitani, E. (2001). A case of prevailing deficit of nonliving categories or a case of prevailing sparing of living categories? Cognitive Neuropsychology, 2001, 18(1), 3970.

Mahon, B.Z., Milleville, S.C., Negri, G.A., Rumiati, R.I., Caramazza, A. and Martin, A. (2007). Action-Related Properties Shape Object Representations in the Ventral Stream. Neuron 55, 507-520, August 2, 2007

Mahon, B.Z., Anzellotti, S., Schwarzbach, J., Zampini, M. and Caramazza, A. (2009). CategorySpecific Organization in the Human Brain Does Not Require Visual Experience. Neuron 63, 397-405, August 13, 2009.

Mahon, B.Z., and Caramazza, A. (2009). Concepts and Categories: A Cognitive Neuropsychological Perspective. Annual Review of Psychology Vol. 60: 27-51. doi:10.1146/annurev.psych.60.110707.163532

Martin, A., Wiggs, C.L., Ungerleider, L.G. And Haxby, J.V. (1996). Neural correlates of category-specific knowledge. Nature, vol. 379, 15 February 1996.

Martin, A., and Chao, L.L. (2001). Semantic memory and the brain: structure and processes. Current Opinion in Neurobiology 2001, 11:194-201

Martin, A. (2007). The Representation of Object Concepts in the Brain. Annu. Rev. Psychol. 2007.58:25-45.

Miceli, G., Capasso, R., Daniele, A., Esposito, T., Magarelli, M., Tomaiuolo, F. (2000). Selective Deficit for People's Names Following Left Temporal Damage: An Impairment of Domainspecific Conceptual Knowledge. Cognitive Neuropsychology, 2000, 17(6), 480-516.

Moore, C.J., and Price, C.J. (1999). A functional neuroimaging study of the variables that generate category-specific object processing differences. Brain (1999), 122, 943-962. 


\section{ATL ACTIVITY FOR ANIMALS AND TOOLS}

Mummery, C.J., Patterson, K., Hodges, J.R., Wise, R.J.S. (1996). Proceedings: Biological Sciences, Vol. 263, No. 1373 (Aug. 22, 1996), pp. 989-995.

Murphy, K., Bodzurka, J., and Bandettini, P.A. (2007). How long to scan? The relationship between fMRI temporal signal to noise ration and necessary scan duration. NeuroImage 34 (2007) 565-574.

Nielsen, J.M. (1946). Agnosia, apraxia, aphasia. Their value in cerebral localization. New York: Paul B. Hoeber.

Noppeney, U., Patterson, K., Tyler, L.K., Moss, H., Stamatakis, E.A., Bright, P., Mummery, C. and Price, C.J. (2007). Temporal lobe lesions and semantic impairment: a comparison of herpes simplex virus encephalitis and semantic dementia. Brain (2007), 130, 1138-1147. doi:10.1093/brain/awl344

Papagno, C., Capasso, R. and Miceli, G. 2009. Reversed concreteness effect for nouns in a subject with semantic dementia. Neuropsychologia Volume 47, Issue 4, March 2009, Pages $1138-1148$

Patterson, P., Nestor, P.J., and Rogers, T.T. (2007). Where do you know what you know? The representation of semantic knowledge in the human brain. Nature, vol. 8, December 2007. doi:10.1038/nrn2277

Pelli, D. G. (1997) The VideoToolbox software for visual psychophysics: Transforming numbers into movies, Spatial Vision 10:437-442.

Pietrini, P., Furey, M.L., Ricciardi, E., Gobbini, M.I., Wu ,W.-H.C., Cohen , L., Guazzelli, M. and Haxby, J.V. (2004). Beyond sensory images: Object-based representation in the human ventral pathway. PNAS April 13, 2004 vol. 101 no. 15, 5658-5663.

Raichle, M.E., MacLeod, A.M., Snyder, A.Z., Powers, W.J., Gusnard, D.A., Shulman, G.L. A 


\section{ATL ACTIVITY FOR ANIMALS AND TOOLS}

default mode of brain function. Proc. Natl. Acad. Sci. USA 98, 676-682 (2001).

Rajimehr, R., Young, J. C., Tootell, R. B. H. (2009). An anterior temporal face patch in human cortex, predicted by macaque maps. PNAS February 10, 2009 vol. 106 no. 6 1995-2000.

Rogers, T. T., Hocking, J., Mechelli, A., Patterson, K. and Price, C. (2005). Fusiform Activation to Animals is Driven by the Process, Not the Stimulus. Journal of Cognitive Neuroscience $17: 3$, pp. $434-445$.

Samson, D., and Pillon, A. (2003). A case of impaired knowledge for fruit and vegetables. Cognitive Neuropsychology, 2003, 20 (3/4/5/6), 373-400.

Shmuel, A., Augath, M., Oeltermann, A. and Logothetis, N. 2006. Negative functional MRI response correlates with decreases in neuronal activity in monkey visual area V1. Nature Neuroscience, Vol. 9, n.4, April 2006. doi:10.1038/nn1675

Simmons, W.K., Reddish, M., Bellgowan, P.S.F., and Martin, A. 2009.The Selectivity and Functional Connectivity of the Anterior Temporal Lobes. Cerebral Cortex, doi:10.1093/cercor/bhp149

Smith, A.T., Williams, A.L. \& Singh, K.D. Negative BOLD in the visual cortex: evidence against blood stealing. Hum. Brain Mapp. 21, 213-220 (2004).

Talairach J, Tournoux P (1988). A Co-planar stereotaxic atlas of a human brain. Thieme, Stuttgart Tranel, D., Damasio, H., and Damasio, A.R. (1997). A neural basis for the retrieval of conceptual knowledge. Neuropsychologia, Vol. 35, No. 10, pp. 1319-1327, 1997.

Warrington, E. K. The selective impairment of semantic memory. Q. J. Exp. Psychol. 27, 635657 (1975).

Warrington, E.K., and McCarthy, R. (1983). Category specific access dysphasia. Brain (1983) 


\section{ATL ACTIVITY FOR ANIMALS AND TOOLS}

$106,859-878$.

Warrington, E.K., and Shallice, T. (1984). Category specific semantic impairments. Brain (1984), 107, 829-854 


\section{ATL ACTIVITY FOR ANIMALS AND TOOLS}

Acknowledgements

We thank Scott Fairhall and Thomas McKeeff for their comments, Alex Martin and Yanchao Bi for discussing some neuropsychological findings, Jorge Jovicich for assistance with organizational issues, and Gianpaolo Basso, Manuela Orsini, Claudio Boninsegna and Hanna Liisa Inkala for technical assistance with fMRI. The research was supported by a grant from the Fondazione Cassa di Risparmio di Trento e Rovereto. 
ATL ACTIVITY FOR ANIMALS AND TOOLS

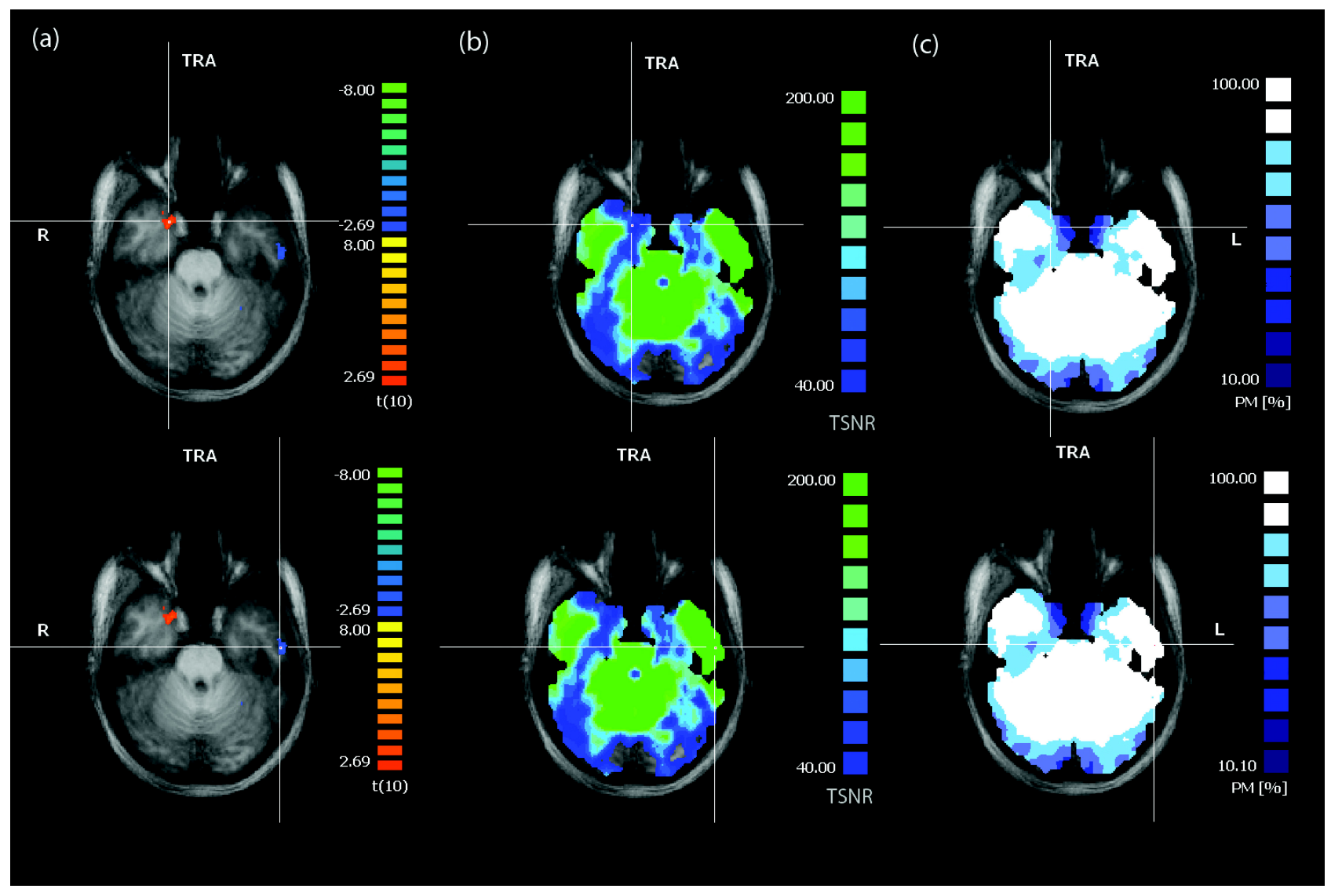


ATL ACTIVITY FOR ANIMALS AND TOOLS

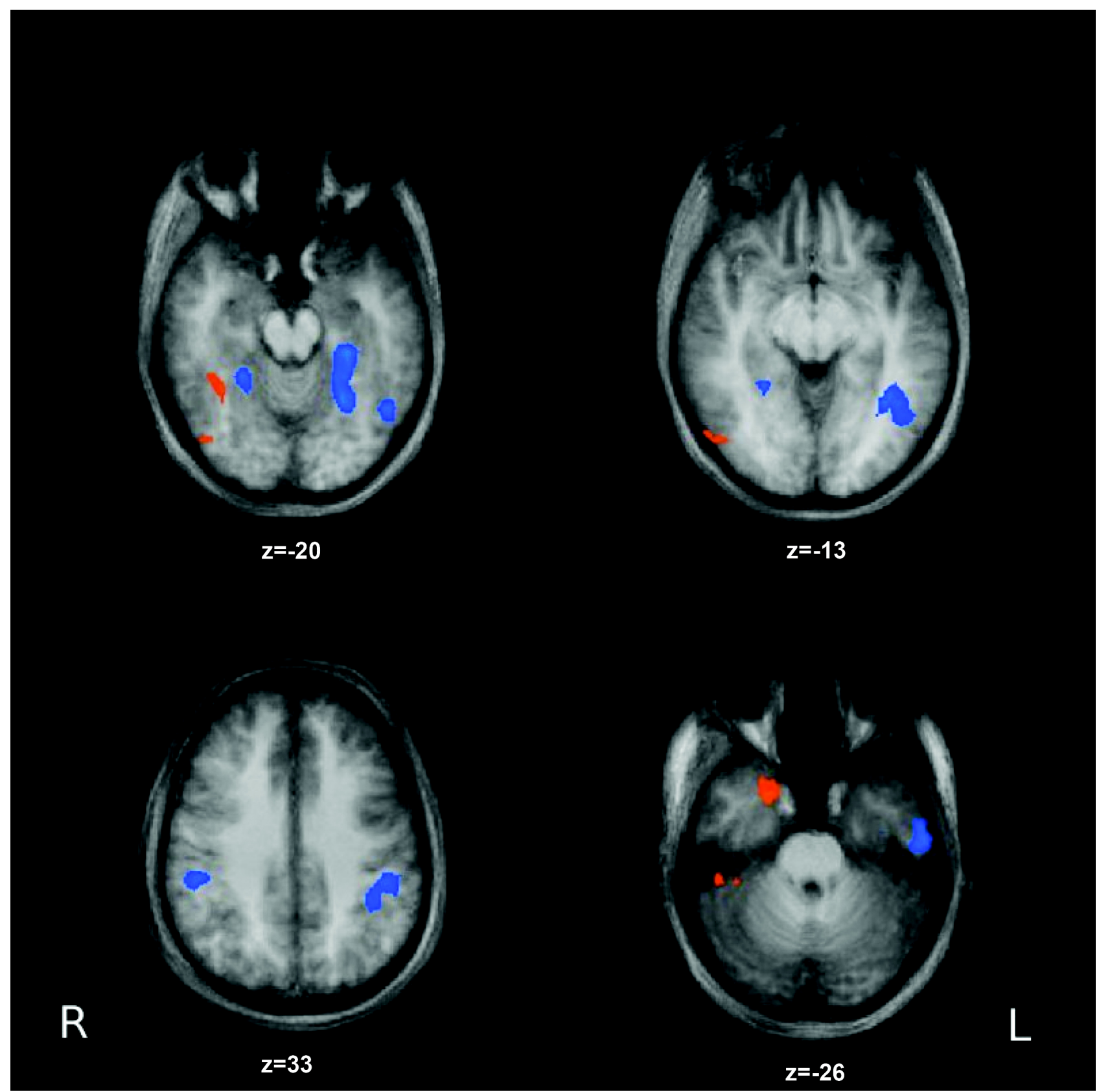




\section{ATL ACTIVITY FOR ANIMALS AND TOOLS}

\section{Beta Values}

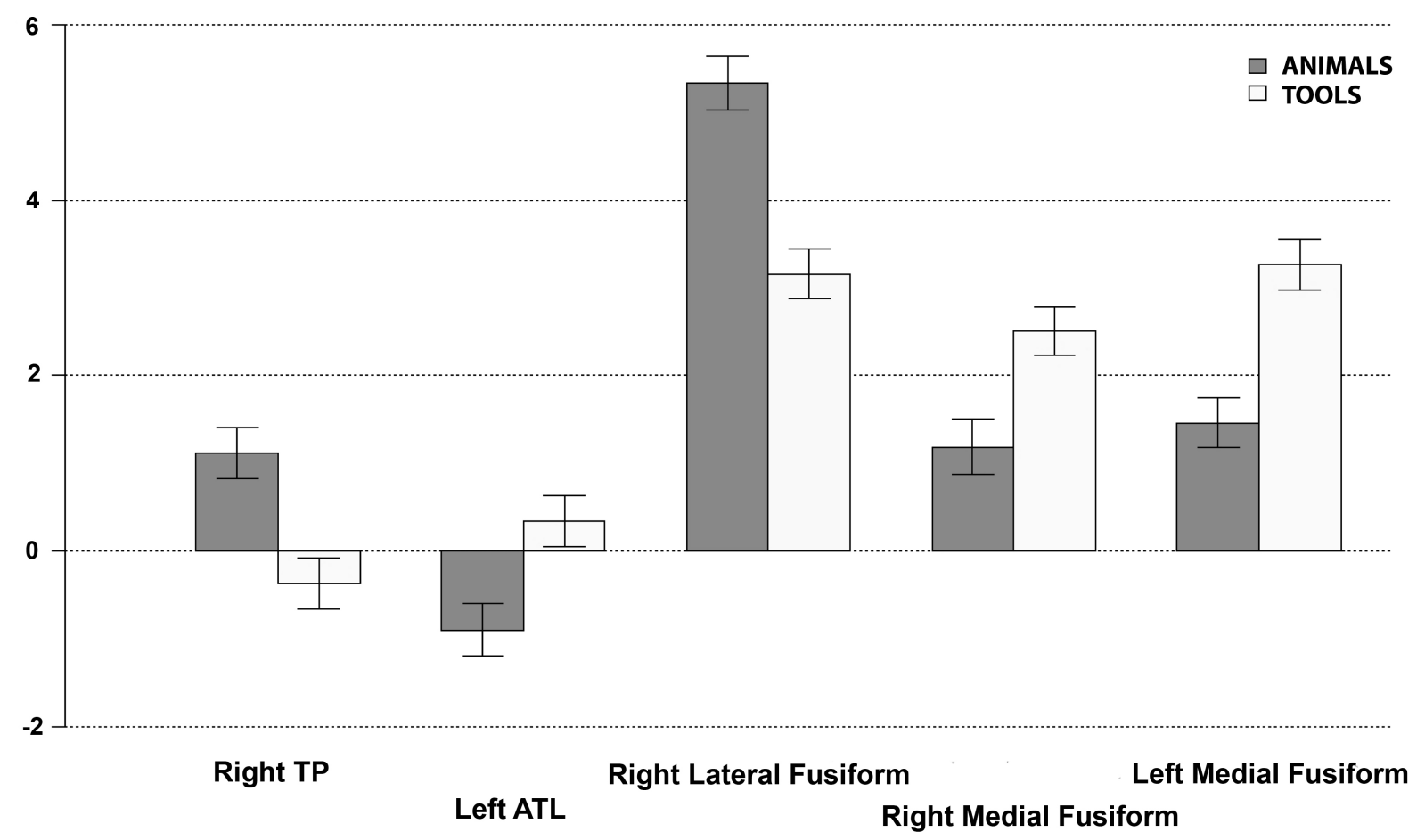

